\title{
Ecos popperianos na metodologia econômica de Elinor Ostrom
}

\author{
Sebastião Neto Ribeiro Guedes \\ Professor - Universidade Estadual Paulista Júlio de Mesquita Filho (UNESP/Araraquara) \\ Endereço: Rodovia Araraquara-Jaú, Km 01 - Machados - Araraquara/SP \\ CEP: 14800-901 - E-mail: sebaneto@fclar.unesp.br

\section{Enéas Gonçalves de Carvalho} \\ Professor - Universidade Estadual Paulista Júlio de Mesquita Filho (UNESP/Araraquara) \\ Endereço: Rodovia Araraquara-Jaú, Km 01 - Machados - Araraquara/SP \\ CEP: 14800-901 - E-mail: : egcarvalho58@gmail.com
}

Recebido: 01/07/2014. Aceite 17/10/2014.

\section{Resumo}

O artigo procura apresentar e analisar a discussão metodológica em economia empreendida por Elinor Ostrom, buscando identificar nela a influência da epistemologia popperiana. A ênfase voltou-se para os conceitos de Princípio da Racionalidade e de Análise Situacional, com os quais Popper contribuiu para a metodologia das Ciências Sociais. O artigo mostrou que esses conceitos encontraram equivalentes na análise da autora, e que Ostrom não apenas reconhece a importância da contribuição popperiana, mas dela faz o ponto de partida para sua proposta metodológica aplicada à governança de recursos comuns. O artigo refere-se, também, ao fato de que ao longo do tempo a metodologia dessa autora gradativamente abre a uma interlocução metodológica mais plural, conservando, no entanto, aspectos essenciais do projeto popperiano para a metodologia em Ciências Sociais, entre os quais a adesão ao individualismo metodológico.

\section{Palavras-Chave}

Elinor Ostrom. Análise situacional. Metodologia em Ciências Sociais. Economia institucional.

\begin{abstract}
The paper has described and analyzed the methodological discussion presented by Elinor Ostrom seeking in it the popperian influence. It focused on the Rationality Principle and Situational analysis concepts trough Popper contributes for Social Sciences methodology. The paper argues that Ostrom recognize the popperian influence and seeks to apply it in her case studies. The paper also shows that the methodology of the author gradually open to a more plural methodological interlocution preserving, despite this, essentials aspects of popperian methodology.
\end{abstract}

\section{Keywords}

Elinor Ostrom. Situational analysis. Methodology in Social Science. Institutional economics.

\section{JEL Classification}

B15. B31. 


\section{Introdução}

A Nova Economia Institucional (NEI) tem mostrado relativa vitalidade no que diz respeito aos avanços agregados à teoria neoclássica pelo seu Programa de Pesquisa Científico. Esse esforço lhe granjeou credibilidade, ampliou o número de seus adeptos e proveu a teoria de estruturas conceituais e objetos de estudo "novos". ${ }^{\text {. Vale dizer, }}$ no sentido lakatosiano, que ela vem ampliando progressivamente o aparato ortodoxo.

Esse claramente é o caso da contribuição teórica de Elinor Ostrom. Esta autora, mais conhecida dos cientistas políticos e sociólogos, aportou pelo menos três grandes contribuições à NEI. Uma diz respeito à descoberta das singularidades que presidem as instituições humanas dedicadas a coordenar recursos de uso comum, cujas características de exclusão custosa e rivalidade no consumo da unidade de recursos nem sempre encontram no mercado ou no estado formas adequadas de governança (Ostrom, 2003; Ostrom, 2010; Ostrom, 2012); a segunda repousa em reafirmar, em termos novos e mais complexos, a hipótese formulada desde Smith, da possibilidade de instituições auto-organizadas (Ostrom, 2010) ; a terceira diz respeito à contribuição para a discussão do método que, a partir de um ponto de vista fortemente influenciado pelas contribuições metodológicas popperianas, almeja uma estrutura conceitual que seja capaz de unificar conceitualmente as Ciências Sociais (Ostrom, 1986; Ostrom, 1990;Ostrom, 1991). Nesse último aspecto, não é exagero afirmar que, dos novos economistas institucionais, ela seja a que mais ampla e exaustivamente tenha enfrentado os problemas metodológicos em economia.

Uma ressalva se faz necessária. $\mathrm{O}$ artigo não afirma de modo algum que Ostrom tenha adotado plena e integralmente o método de Popper, mas que este inspirou e influenciou fortemente a própria proposta metodológica da ganhadora do prêmio Nobel de Economia de 2009. Essa afirmação implica, também, como se irá discutir nesse texto, numa "demarcação" mais precisa do campo epistemológico no

1 Basta referir, a respeito do prestígio e poder da nova economia institucional, o fato de que três dos seus representantes (Douglass North, Oliver Williamson e Elinor Ostrom) foram, em período recente, agraciados com o prêmio Nobel de Economia. Ademais, Zylicz (2009) defendeu a pertinência e relevância da NEI mesmo diante do amplo questionamento ao Programa de Pesquisa Científico Neoclássico colocado pela crise econômica mundial do capitalismo a partir de 2008. 
qual se encontra a autora, desfazendo assim tentativas recentes de alguns analistas de aproximá-la da matriz teórico-metodológica do pragmatismo do institucionalismo original.

A pertinência de Popper como fundamento metodológico de Ostrom aparece em pelo menos quatro aspectos. Primeiro, na adesão de ambos ao postulado do individualismo metodológico, que toma o indivíduo como protagonista e unidade de análise sem, contudo, recorrer ao psicologismo; segundo, porque ambos endossam uma abordagem racionalista e uma compreensão similar quanto à natureza da ciência (sociais) e das suas características: compreensão e predição; terceiro, porque em ambos o teste empírico serve ou como critério capaz de falsear uma teoria, ou como elemento capaz de disciplinar os excessos da abstração dedutiva. Neles, há um claro compromisso metodológico entre dedução-indução, embora à primeira caiba a primazia; por fim, a abordagem de ambos adere ao exame dos fatores situacionais ou de contexto que restringem ou condicionam a ação individual, bem como permite que a ação de outros atores, instituições etc., sejam interpretadas como fatores restritivos da ação individual (Schmid, 1988).

Sendo assim, o artigo pretende discutir a influência e o alcance da reflexão popperiana sobre a metodologia de Ostrom, principalmente no seu livro Governing the commons. Para isso, o artigo está dividido em duas seções, além desta introdução. Na primeira, discute-se rapidamente a contribuição metodológica de Popper, centrando o foco em suas reflexões sobre a metodologia das Ciências Sociais. Mais especificamente, procura-se discutir sua proposta para as Ciências Sociais (cujo modelo de ciência era a Economia) contida nos conceitos de "Princípio da Racionalidade" e de "Análise situacional", este último apropriado por Ostrom, como se verá, por meio do conceito de "situação da ação" ou "arena da ação". Na segunda parte, a discussão volta-se para a proposta metodológica de Ostrom a partir do livro já citado, buscando nele e em outros estudos identificar o vínculo da autora com a abordagem metodológica inspirada por Popper. $\mathrm{O}$ artigo termina com a apresentação das conclusões. 


\section{A Economia como campo de experimentação metodológico de Popper}

A intenção deste tópico não é a de comentar exaustivamente a contribuição de Popper à metodologia científica. Todavia, uma incursão, ainda que ligeira, é necessária para se entender sua contribuição à metodologia em economia e a influência que ela exerceu sobre Ostrom.

Como se sabe, a discussão sobre a natureza da descoberta científica levou Popper a se distanciar dos positivistas lógicos em relação, principalmente, aos critérios de demarcação do que era ou não ciência. Para os positivistas lógicos, a ciência era um exercício teórico e prático, cujos resultados poderiam (ou não) ser corroborados pelas evidências empíricas. Inexistindo tal condição, o conhecimento era considerado não científico. Nesse sentido, a filosofia e a religião eram conhecimentos significativos, mas não científicos.

Esse procedimento não satisfazia plenamente a Popper por pelo menos três motivos (Popper, 1980): 1) conferia à indução um papel central na edificação do discurso científico, desconsiderando as críticas que desde Hume vinham sendo feitas ao "problema da indução"; 2) o critério positivista não excluía do status científico um conjunto de conhecimentos que Popper julgava não científicos, embora recorressem aos fatos e às evidências para sua corroboração, tais eram os casos da psicanálise, do marxismo e da psicologia de Adler, ao mesmo tempo em que dele excluía conhecimentos claramente científicos, como a astronomia; 3) a posição positivista conservava firme adesão ao essencialismo, isto é, à busca pela "verdade" ou conteúdo último dos fenômenos, que era permanente e constitutiva do estoque de conhecimentos humanos.

O modo como Popper criticou a proposta positivista é bastante conhecido, assim como seu corolário falseasionista (Popper, 1975 e 1980). Em relação a este último, cabem alguns comentários. Para Popper, ao invés de ser corroborada pelos fatos, uma teoria deveria especificar, ex ante, as condições empíricas em que poderia ser refutada. Uma vez que uma hipótese (logicamente consistente) formulada pudesse gerar previsões, seria requerido dela a descrição das condições sob as quais ela poderia ser invalidada e, assim, descartada. Desse modo, o que se requer da ciência é a especificação não da 
sua fortaleza, mas da sua fraqueza. Esse era, na visão de Popper, o modo como a ciência avançaria, por meio da crítica lógica às hipóteses falseáveis e sua substituição por outras mais robustas.

Nas palavras de Hands (1992:20/21):

Brevemente, e negligenciando um conjunto de questões filosóficas, a metodologia falsificacionista de Popper exige que a pesquisa por conhecimento científico proceda do seguinte modo. Comece com uma situação problema científico: algo que requeira explicação científica. Em seguida, proponha uma conjectura destemida que possa oferecer uma solução para o problema. Depois, teste com rigor a conjectura comparando sua menos provável consequência com os dados empiricos relevantes.... Finalmente, o último movimento no jogo depende de como a teoria se comporta durante o terceiro estágio de testes. Se as implicações da teoria não foram apoiadas pela evidência, a conjectura é falsificada e deve ser substituída por uma nova teoria que não é ad hoc relativamente à original. Se a teoria não foi falsificada então ela é considerada corroborada pelo teste e é aceita provisioriamente. Deve-se observar que dado o falibilismo de Popper, esta aceitação é provisória para sempre; o método não garante que a teoria sobrevivente seja verdadeira, apenas que ela enfrentou um oponente duro e venceu. [Observação: todas as citações diretas em língua estrangeira encontradas nesse texto foram traduzidas pelo autor do artigo]

Além dos apelos ideológicos (defesa de uma sociedade "livre" com ataque simultâneo ao comunismo), a proposta falseasionista de Popper caiu no gosto dos economistas (ainda que sua adesão prática a ela seja duvidosa) porque oferecia também uma alternativa ao debate, particularmente intenso entre eles, entre dedução versus indução, pois o falseasionismo é consistente com o apriorismo dedutivo, ao permitir que hipóteses sejam formuladas com base na introspecção ou na suposição de ação racional, bem como com a tradição histó- 
rico-indutivista, já que o falseasionismo exige o teste empírico e a "disciplina dos dados" (Hands, 1992:21/22).

No que diz respeito às Ciências Sociais, Popper se dedicou mais detalhadamente a ela no final da sua vida, no contexto profissional em que foi professor no departamento de Economia da London School of Economics. ${ }^{2}$ Seu olhar se voltou para aquela dentre todas as Ciências Sociais cujos resultados, segundo acreditava, estavam mais próximos do status científico: a Economia (Popper, 1993; Popper, 1985; Ganem, 2012). É num artigo de 1967 que Popper estabeleceu duas referências que se mostrarão fundamentais para o projeto teórico de Ostrom, o princípio da racionalidade e o da estrutura situacional. $\mathrm{O}$ artigo aproximou Popper dos problemas metodológicos próprios das Ciências Sociais e, por essa razão, apresentaremos seu argumento com detalhe para em seguida analisar seu alcance.

Nesse artigo (Popper, 1985), ele partiu da distinção entre explicações de eventos singulares (Quando ocorrerá o próximo eclipse lunar? Quando acontecerá a elevação da taxa de desemprego no Oeste de Ontário?) e de tipos ou classes de eventos (Por que o eclipses lunares sempre ocorrem quando há lua cheia? Por que da elevação e decréscimo sazonais no desemprego na indústria da construção civil?). Aquele encontrava solução sem a necessidade de um modelo; este necessita de tais modelos. Segundo Popper, nas Ciências Sociais não é possível explicações/previsões para eventos singulares, mas ao tratar de eventos de tipo ou classes suas explicações são similares às das ciências naturais. Essa diferenciação levou autores como Hands (1992) e Fernandez (2012) a identificarem nela um recuo de Popper em relação ao monismo metodológico de escritos anteriores e a estabelecer um primeiro movimento acerca da metodologia em Ciências sociais que contradiz muitas das suas afirmações sobre a natureza da ciência em geral.

O contraponto entre as ciências naturais e sociais o levou a afirmar que o modelo (um artefato mental/material que articula elementos para a explicação) nas ciências naturais é "animado" pelas leis e princípios gerais que a ciência cuida de descobrir. Nas Ciências sociais,

2 Essa afirmação deve ser relativizada no sentido de que, ainda que de forma incipiente, já em Miséria do historicismo, de 1944, a defesa de uma "lógica da situação" para as Ciências Sociais já estava presente na obra de Popper, em especial no seu comentário à "teoria" da história presente no livro Guerra e Paz de Tolstoi (Popper, 1993:115/116). 
o modelo (a explicitação dos elementos que compõe uma situação) é animado pelo princípio da racionalidade.

Por situação ou análise situacional, Popper entendia os elementos objetivos e subjetivos constitutivos do contexto no qual os indivíduos interagem e tomam decisões. A situação incluía o meio físico e social, as instituições e as inclinações e percepções subjetivas dos agentes. Apesar disso, Popper reafirma - numa clara adesão ao individualismo metodológico - o protagonismo dos indivíduos, porque são eles, e não as instituições, que agem (Ganem, 2012:100).

E os indivíduos aparecem no princípio da racionalidade, que o próprio Popper (1985:359) definiu como a condição na qual "varias pessoas ou agentes envolvidos agem adequadamente ou apropriadamente, ou seja, conforme a situação". Uma tentativa de esclarecimento foi dada pelo próprio Popper, para o qual o princípio da racionalidade não é:

1. Uma afirmação a priori valida, pois uma simples observação mostrará que nem todos os indivíduos (e nem sempre) agem de maneira adequada à situação (há diferenças pessoais não só em conhecimento e habilidades, mas em avaliar e entender a situação). Por isso, o princípio da racionalidade é falso, já que um princípio que não é universalmente verdadeiro é falso;

2. Uma afirmação que possa ser falseada (por que é falso?);

3. Uma afirmação que possua conteúdo psicológico concreto;

4. Uma tautologia, porque está é verdadeira, ao passo que o princípio da racionalidade não.

Se o princípio da racionalidade é falso, o modelo deve ser também falso. Apesar disso, argumenta Popper, ele é a melhor aproximação da verdade porque a) é mais informativo, interessante e testável, e embora o princípio da racionalidade possa ser um fator contribuinte para a refutação do modelo, a principal responsabilidade por isso é do próprio modelo; b) conduz a menos arbitrariedades. A esse respeito, Ganem (2012:100) observou que o conceito de aproximação da verdade é essencial para a análise situacional de Popper, pois legitima os problemas lógicos e empíricos nela contidos.

A análise situacional então combina o contexto da situação e o princípio da racionalidade de maneira a prover o método, nas palavras 
de Popper, com situações sociais típicas (1985:358). Uma descrição bastante oportuna da análise situacional foi dada por Hands (1992:27/28), para quem:

Conforme a análise situacional de Popper, a explicação do comportamento humano deveria proceder como se segue. Suponha que o problema é explicar porque o agente A engajou-se em um tipo particular de comportamento, digamos X. O primeiro passo na explicação desse comportamento é descrever a "situação" do agente no momento em que o comportamento em questão aconteceu. Esta descrição da situação do agente normalmente incluirá tanto componentes subjetivos (os objetivos, as crenças, os desejos etc do agente) quanto componentes objetivos (constrangimentos físicos e sociais que o agente enfrenta). O segundo passo na explicação é o de prover uma análise da situação; especificar que tipo de comportamento deveria ser apropriado (isto é, racional) dado a situação do agente. A terceira parte da explicação é adicionar, e esta é a chave, o princípio da racionalidade (PR), que afirma que todos os indivíduos agem de fato de uma maneira que é apropriada à situação (ou seja, eles agem racionalmente). Este PR permite-nos deduzir a ação do agente da descrição da sua "situação" e da nossa análise do que constitui um comportamento adequado.

A natureza do princípio da racionalidade foi o aspecto da metodologia de Popper mais polêmico. Vários autores questionaram desde sua natureza metafísica (Schmid, 1988), passando pela imprecisão e desconfiança que ele inspira se se deseja produzir conhecimento científico (Fernandez, 2012), até sua incompatibilidade com a metodologia falseasionista proposta pelo próprio Popper (Oakley, 1990).

Além disso, a distinção entre Ciências Sociais e da Natureza oferecida por Popper traz um problema no mínimo constrangedor. Nas Ciências da Natureza, segundo ele, a lógica do método científico é animada pelas leis gerais da física. Seriam aceitáveis os termos 
aplicados por Popper para as Ciências Sociais? De que o seu princípio "animado" seja falso, tal como o Princípio de Racionalidade que anima as Ciências Sociais?

Do mesmo modo, conforme observou Hands (1992), a solução de Popper para a metodologia em Ciências Sociais embute problemas de dois tipos. De um lado, a proposta de análise situacional implica a "imunização" permanente de parte da teoria pertinente ao comportamento dos agentes (pois não pode ou deve ser falseada) e, de outro lado, "não oferece explicação para os mecanismos que conectam a situação com a ação". Em outras palavras, ela não enfrenta de maneira satisfatória a questão da teoria da escolha, afinal "os economistas devem ainda tomar decisões sobre como os fatos influenciarão suas escolhas, como modificar a especificação da situação do agente quando a predição falha, qual consideração não empírica pode influenciar a teoria da escolha etc." (Hands, 1992:30).

\section{Agente e situação na metodologia de Ostrom}

A contribuição metodológica de Ostrom à compreensão das instituições e sua heterogeneidade é construída a partir dos termos sugeridos por Popper. De um lado, os princípios que "animam" os agentes e, de outro, a estrutura de situação na qual eles se encontram e interagem. A estrutura conceitual "equivalente" na proposta de Ostrom é a de "arena da ação", que contém um duplo: a situação da ação (condições materiais e biofísicas, atributos da comunidade e as regras) e os seus participantes (comportamento individual). A construção dessa estrutura conceitual simétrica à de Popper atravessa toda a obra da autora e tem no livro Governing de Commons, de 1990, um importante marco de referência, razão pela qual será feita uma análise mais pormenorizada dessa obra, pois nela encontram-se, além da base mais sólida dos avanços posteriores da metodologia de Ostrom, também seu momento mais "forte" de adesão às sugestões popperianas. 


\subsection{Os primeiros passos da metodologia de Ostrom em "Governing de Commons"}

O livro Governing the Commons, publicado em 1990, é sem dúvida a obra mais importante de Elinor Ostrom, pois consolida a temática sobre a qual sua reflexão teórica se dedicou desde seus inícios como jovem pesquisadora. ${ }^{3}$, como também os termos da discussão metodológica que será recorrente em sua vasta obra. Em relação à temática, ela estabeleceu a pertinência e relevância de se estudar a governança dos "recursos de uso comum", bem como entender porque algumas formas de governança foram bem-sucedidas ao longo do tempo e outras não, mostrando ao mesmo tempo antecipação e grande sintonia com a agenda sobre a "governança ambiental" (Araral, 2013). Em relação ao método, por refletir sobre as dificuldades de se construir uma base empírica para ciências tais como a economia que se baseiam no poder de teorias dedutivas derivadas de um número mínimo de hipóteses básicas sobre o indivíduo e sobre como os indivíduos se relacionam uns com os outros e com o mundo físico. (Ostrom,1990: 237), bem como sobre o papel do indivíduo na explicação científica em ciências sociais, a partir de uma perspectiva de interação indivíduo-regra (norma).

No livro citado, seu foco são as instituições que lidam com recursos de uso comum (common-pool resources), que diferiam dos recursos privados, assim como dos recursos públicos (ou estatais). Para uns e outros, segundo Ostrom, a teoria institucional havia provido razoável aporte teórico e empírico, seja por meio da teoria da firma (Coase, Williamson, etc.), seja por meio da teoria da ação coletiva (Olson, etc.).

Seu ponto de partida em Governing the commons é a fuga da dicotomia privado-estatal, que impregnava a discussão sobre os recursos coletivos. No livro, a autora analisou três modelos que lidaram com os problemas vinculados a esses tipos de recursos. O mais famoso deles, conhecido como "a tragédia dos comuns", foi assim batizado por Hardin para caracterizar os efeitos devastadores sobre os recursos comuns da atividade econômica sobre eles exercida por

3 Bish (2013:230) identificou a origem do tema que ela perseguiu quase sem interrupções ao longo da vida no ano de 1965, quando Ostrom defendeu, na Universidade da Califórnia (UCLA), sua dissertação de mestrado intitulada Public entrepreneurship: a case study in Ground Water Basin management. Além do tema, essa dissertação também estabeleceu o apreço de Ostrom por trabalhos empíricos. 
agentes racionais que buscavam livremente seus próprios interesses. Havia nesse caso uma clara divergência entre o interesse comum de preservar os recursos no longo prazo e os objetivos de maximização individuais de curto prazo.

O segundo modelo remetia à teoria dos jogos e dizia respeito à formalização em termos do dilema do prisioneiro do problema proposto por Hardin, alcançando as mesmas conclusões do modelo anterior.O terceiro modelo, baseado na ação coletiva de Mancur Olson, colocava dúvidas sobre se a percepção por parte de agentes individuais de que um interesse comum pudesse beneficiá-los seria suficiente para promover voluntariamente a ação coletiva. As conclusões desses modelos se inclinavam ora em favor de uma força externa capaz de garantir a cooperação e a coordenação necessárias para evitar a tragédia dos comuns (Leviathan as the only way), ora na defesa da privatização dos recursos comuns, por meio de mudanças nos direitos de propriedade (privatization as the only way). A crítica de Ostrom localiza-se em três níveis: num primeiro, ela afirma que (Ostrom, 1990:14)

Tanto os defensores da centralização quanto os defensores da privatização aceitam como aspecto central que a mudança institucional deva vir de fora e ser imposta sobre os indivíduos afetados. Apesar de partilharem a fé na necessidade e eficiência do "estado" para a mudança institucional com a finalidade de aumentar a eficiência, a mudança institucional que eles recomendam dificilmente poderia estar mais divorciada uma da outra.

Num segundo nível, ela observou que (Ostrom, 1990: 14)

A capacidade dos indivíduos livrarem-se de vários tipos de situações dilemas varia de situação para situação....as instituições raramente são privadas ou públicas - "o mercado" ou "o estado". Muitas instituições de uso de recursos comuns bem sucedidas são misturas ricas de instituições "privadas" e "públicas" que desafiam a classificação em dicotomias estéreis. 
Em razão dessas observações, a autora buscou explicitamente entender os mecanismos de autogoverno presentes nas instituições de uso de recursos de uso comuns exitosos. Conforme suas próprias palavras (Ostrom, 1990:27):

Espero que essas conjecturas contribuam para o desenvolvimento de uma teoria da auto-organização e do autogoverno empiricamente válidas para pelo menos um bem definido universo de situações problemas. Este universo contém uma proporção substancial de recursos renováveis pesadamente utilizados pelos seres humanos em diferentes partes do mundo.

Um terceiro tipo de crítica, presente nas duas anteriores, dirige-se à ausência de conteúdo empírico dos modelos, tornando-os, quando muito, aplicáveis a situações especiais (Ostrom, 1990:186/7).

A argumentação da autora a esse respeito é longa, e se funda na distinção entre modelo e estrutura. Para ela, os modelos, utilizados por todas as vertentes tradicionais de ação coletiva, são recursos mentais utilizados com propósitos de realizar previsões acerca do comportamento individual e dos resultados esperáveis de variáveis em uma dada situação. Por sua própria natureza eles devem ser construídos sobre hipóteses simples e gerais sobre o comportamento dos indivíduos, ao mesmo tempo em que convertem um conjunto de fatores e contextos em parâmetros. A situação torna-se, assim, um elemento dado, sobre a qual os indivíduos não podem exercer ação transformadora. Segundo ela, os modelos são úteis para prever situações de grandes recursos de uso coletivo, em que os agentes não se comunicam, agem de maneira independente, não despendem nenhum esforço para analisar os efeitos da ação de um indivíduo sobre os outros e os custos para alterar a situação dada são altos.

Ao contrário disso, a noção de estrutura supõe observações acerca do contexto de problemas com os quais lidar, bem como com a estrutura de incentivos disponíveis. Na estrutura existe uma ampla lista de variáveis que devem ser utilizadas para caracterizar a situação conforme sua pertinência. Nas palavras de Ostrom (1990:192) 
De uma estrutura não se deduz uma previsão precisa. De uma estrutura, derivam-se as questões que necessitam ser feitas para clarificar a estrutura de uma situação e os incentivos com os quais os indivíduos se deparam. Uma vez que os incentivos são aclarados, o teórico pode analisar uma situação e prever o comportamento provável em termos de escolha de estratégia, $e$ as conseqüências que são prováveis esperar.

As similaridades, inclusive em termos de linguagem com a análise situacional de Popper, são enormes. Além disso, o projeto teórico da autora de prover uma teoria da ação coletiva quando os indivíduos lidam com instituições de recursos comuns exigiu uma estratégia empiricista que funcionasse como alternativa às teorias disponíveis, vazias de casos do mundo real. Segundo ela (Ostrom, 1990:25) O que eu tentei fazer nesse volume foi combinar a estratégia utilizada por muitos estudiosos associados com o "novo institucionalismo" com a estratégia usada pelos biólogos para conduzir trabalho empírico relacionado ao desenvolvimento de melhor entendimento teórico do mundo biológico.

No que diz respeito ao elemento que "anima" a estrutura, Ostrom oferece uma explicação para a escolha racional que busca um compromisso entre a racionalidade e a sua irredutibilidade a um comportamento maximizante. ${ }^{4} \mathrm{O}$ expediente - que assumiu a sugestão metodológica da análise situacional de Popper - consiste em submeter a escolha racional a contextos que se modificam, exigindo do indivíduo a articulação de quatro níveis de cognição: 1) a avaliação dos benefícios esperados da ação; 2) a identificação dos custos esperados da ação;3) as normas internas que amparam, condicionam e dão sentido à ação individual; 4) a taxa de desconto aplicada ao resultado futuro esperado do recurso de uso comum.

São elas características que afetam as escolhas individuais de estratégias em qualquer situação. Sendo assim, é razoável prever que os indivíduos escolherão estratégias que ofereçam expectativas de benefícios maiores do que as de custo. Mas são as várias situações, co-

4 Segundo Ostrom "Se os indivíduos encontram regras que funcionam relativamente bem, eles podem ter pouca motivação para continuar o custoso processo de buscar regras que funcionarão melhor" (Ostrom, 1990:211). 
locadas fora dele, que determinam os custos e benefícios esperados. ${ }^{5}$ Com esse expediente, a autora escapa também ao psicologismo, tarefa com a qual, como vimos, Popper se empenhou vivamente. Aliás, é à autoridade de Popper que Ostrom (1990:38) recorre quando afirma que: Esta concepção geral é um modo de realizar o conselho de Popper para fazer do princípio da racionalidade "um princípio quase vazio". Ele coloca o peso fundamental da análise teórica na especificação rigorosa e cabal de modelos de situação nas quais os indivíduos se encontram.

$\mathrm{Na}$ verdade, para Ostrom, o comportamento racional é apenas um daqueles comportamentos possíveis. A autora sugere que a adoção de múltiplos modelos seja desejável em vista de prover a análise com hipóteses mais realistas de agentes conforme o contexto. Além disso, permitiria selecionar e combinar diferentes hipóteses sobre o comportamento individual que, nem por isso, ameaça a própria coerência da adesão ao individualismo metodológico.

Ao mesmo tempo, é possível afirmar que a adesão à proposta popperiana parece não oferecer dificuldades a autora no sentido de atender às duas condições fundamentais daquele projeto: 1) prover um conjunto de hipóteses ou teorias gerais que explicam os casos de êxito e fracasso no uso dos recursos comuns, que no caso são os principles design; 2) a explicitação das condições nas quais a teoria poderia ser falseada, caso em que se encontrasse um (ou vários) exemplo de êxito na governança dos recursos de uso comum em que estivessem ausentes os sete princípios (ou pelo menos a maioria deles), ou de fracasso em que eles estivessem presentes (ou pelo menos a maioria deles). Nesse aspecto, a influência hard popperiana conduziria a autora quase a abraçar o falseasionismo.

Os capítulos 3 e 5 do livro "Governing the commons" (1990) são dedicados à análise de rico material empírico coletados de sua própria experiência de pesquisa e de casos estudados por terceiros. No capítulo 3 são apresentados exemplos variados de êxito na gestão de recursos de uso comum, tais como a gestão de campos de pastagens e florestas em regiões montanhosas na Suíça e Japão, da gestão de recursos hídricos para irrigação em vários municípios de uma região

5 Bish (2013:231) sugere, ainda, que tanto Elinor quanto Vincent Ostrom, seu marido, estejam mais próximos da tradição austríaca no que diz respeito à abordagem do mercado do que dos neoclássicos tradicionais. Por essa razão, eles preferem enfatizar os processos de informação e incentivos do que os de equilíbrio e otimização. 
semi-árida na Espanha e, também, de projetos de irrigação em algumas aldeias nas Filipinas.

O êxito em questão é constatado ex post, por meio da longevidade dos arranjos institucionais na garantia de apropriação de unidades de recursos aos indivíduos, ao mesmo tempo em que lhes garante a sustentabilidade do sistema de recursos. Esse tipo de solução contorna o campo movediço em que poderia ser lançada a discussão se se afirmasse que houve maximização ou otimização no uso dos recursos. Os casos são exitosos simplesmente porque os arranjos institucionais são "bem-sucedidos" em termos de longevidade (nos casos do Japão e Suiça por mais de 500 anos) e capazes de prover a reprodução sustentada dos fluxos e estoques de recursos comuns.

No capítulo 5, à guisa de contraste, são apresentados casos de fracasso na gestão de tais recursos, bem como casos ambíguos, caracterizados como de fragilidade. Do primeiro tipo são os casos dos arranjos de governança coletiva construídos para lidar com duas áreas de pesca na Turquia e uma no Sri Lanka, e de projetos de irrigação na Califórnia. Do segundo tipo são alguns casos de pesca em Port Lameron e Alanya no Canadá e Turquia, respectivamente.

A análise desses casos extremos permitiu a elaboração de uma estrutura analítica, esboçada no capítulo 4, chamada de "design principles". Tais princípios - as "conjecturas" de Popper - estavam presentes nos casos exitosos, e ausentes em grande proporção nos casos de fracasso. Os princípios eram os seguintes:

1. Fronteiras definidas com clareza, de maneira que sejam identificados sem ambigüidades os indivíduos/famílias que têm direitos para retirar unidades de recursos dos bens comuns, assim como definidas as fronteiras dos próprios bens comuns $\rightarrow$ reduz ou elimina problemas de free rider;

2. A congruência entre as regras de apropriação e de provisão e as condições locais $\rightarrow$ evitar regras que mesmo lidando com um mesmo tipo de recurso comum (por exemplo, sistemas de irrigação) desconsiderem as especificidades e particularidades de cada caso;

3. Arranjos de escolha coletiva para que a maioria dos indivíduos que são afetados pelas regras operacionais possa participar na modificação de tais regras $\rightarrow$ aumenta o compromisso co- 
letivo dos indivíduos na medida em que regras externas originadas da autoridade não podem ser impostas na atividade cotidiana;

4. Sistema de monitoramento, cuja função é auditar as condições dos bens comuns e o comportamento dos apropriadores, subordinado aos apropriadores ou geridos por eles mesmos $\rightarrow$ fortalece nos indivíduos o autocomprometimento a regras;

5. Sanções graduadas. Apropriadores que violam as regras sofrem punições graduadas por parte dos outros apropriadores, por funcionários contratados ou ambos, dependentes da seriedade e contexto da ofensa $\rightarrow$ fortalece o autocomprometimento a regras nos indivíduos;

6. Existência de mecanismos de resolução de conflitos que ofereçam aos apropriadores ou seus representantes o acesso rápido a arenas locais de baixo custo para a resolução de confitos (entre os próprios apropriadores ou entre esses e seus representantes) $\rightarrow$ melhora a governança, tendo em vista o fato de que toda e qualquer regra é passível de conter ambiguidades, ainda que sejam os apropriadores os seus agentes de monitoramento e de sancionamento;

7. A existência de um mínimo de direitos de modo que os apropriadores possam conceber suas próprias instituições sem que sejam impedidos ou desafiados por autoridades governamentais externas $\rightarrow$ sugestão de que a ação coletiva é capaz de instituir condições de "autogoverno";

8. Para bens comuns que são parte de um sistema maior, partir de instituições menores, enraizadas na prática social dos indivíduos, oferece sólidas bases para a construção de instituições maiores, em níveis e abrangência diferenciados (nested enterprises) $\rightarrow$ o capital social inicial capacita a lidar melhor com problemas maiores e de maior abrangência.

Esse conjunto de princípios permitiu a Ostrom uma avaliação bastante interessante do desempenho dos arranjos institucionais, conforme transparece no quadro abaixo, retirado da autora. 


\begin{tabular}{|c|c|c|c|c|c|c|c|c|c|c|c|c|c|c|}
\hline 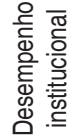 & 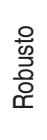 & $\begin{array}{l}\text { 음 } \\
\text { 응 } \\
\text { ه }\end{array}$ & 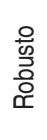 & 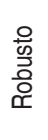 & 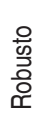 & $\begin{array}{l}\frac{0}{00} \\
\text { 응 } \\
\text { ه }\end{array}$ & 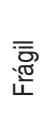 & $\begin{array}{l}\text { 产 } \\
\text { 胥 }\end{array}$ & $\begin{array}{l}\overline{\overline{7}} \\
\text { 离 }\end{array}$ & 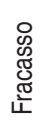 & 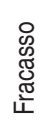 & 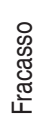 & 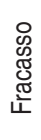 & 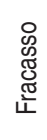 \\
\hline 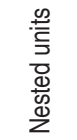 & 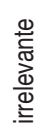 & 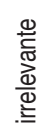 & $\frac{E}{\omega}$ & $\frac{E}{\omega}$ & $\frac{E}{\omega}$ & $\frac{E}{\omega}$ & 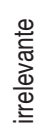 & हE & 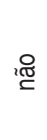 & 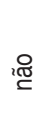 & 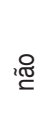 & i̊ & શ్ֶ & $\stackrel{\text { i̊ }}{\stackrel{2}{c}}$ \\
\hline
\end{tabular}

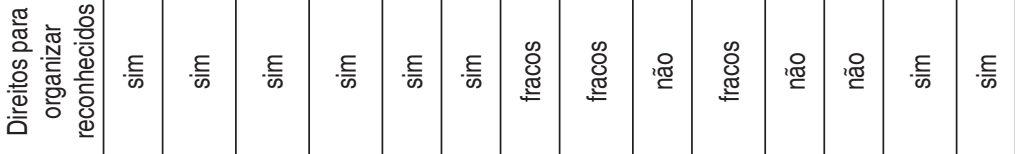

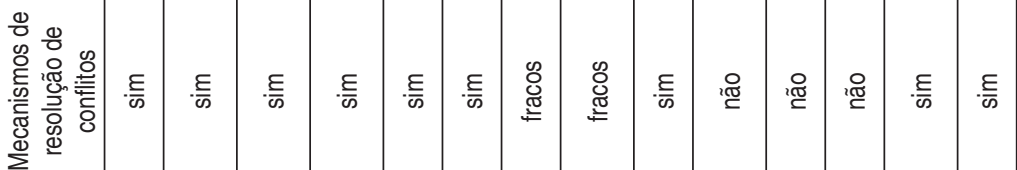

\begin{tabular}{|c|c|c|c|c|c|c|c|c|c|c|c|c|c|c|}
\hline 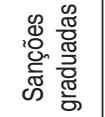 & $\frac{E}{\omega}$ & $\frac{E}{\omega}$ & $\frac{E}{\omega}$ & $\frac{E}{\omega}$ & $\frac{E}{\omega}$ & . $\frac{E}{\omega}$ & $\frac{E}{\omega}$ & 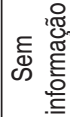 & $\frac{E}{\omega}$ & I્ટ & $\frac{E}{\omega}$ & ז̊̊ & 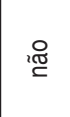 & શָ \\
\hline 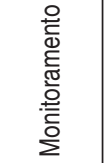 & $\frac{E}{\omega}$ & $\frac{E}{\omega}$ & $\frac{E}{\omega}$ & $\frac{E}{\omega}$ & $\frac{E}{\omega}$ & $\frac{E}{\omega}$ & है & $\frac{E}{\omega}$ & .E & શ્̊ & $\frac{\varepsilon}{\omega}$ & ஜ্ׁে & ז̊̊ి & ז̊ \\
\hline 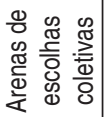 & $\frac{\varepsilon}{\omega}$ & $\frac{\varepsilon}{\omega}$ & $\frac{E}{\omega}$ & $\frac{\varepsilon}{\omega}$ & $\frac{E}{\omega}$ & $\frac{E}{\omega}$ & $\begin{array}{l}\stackrel{\mathscr{J}}{\mathbb{\Phi}} \\
\stackrel{\mathbb{t}}{=}\end{array}$ & $\frac{\varepsilon}{\omega}$ & 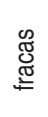 & 2ָ & ז̊̊ & ị̊̊ & શ્ & $\frac{E}{\omega}$ \\
\hline 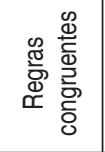 & $\frac{E}{\omega}$ & $\frac{\varepsilon}{\omega}$ & $\frac{E}{\omega}$ & $\frac{\varepsilon}{\omega}$ & $\frac{E}{\omega}$ & $\frac{E}{\omega}$ & है & $\frac{\varepsilon}{\omega}$ & $\frac{E}{\omega}$ & શ્ల & है & ז̊̊ & ז̊ષ & શ̊ \\
\hline 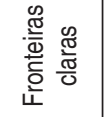 & $\frac{E}{\omega}$ & $\frac{E}{\omega}$ & $\frac{E}{\omega}$ & $\frac{E}{\infty}$ & $\frac{E}{\omega}$ & $\frac{E}{\omega}$ & Iָ & $\frac{E}{\omega}$ & $\frac{E}{\omega}$ & ז̊ & $\frac{280}{2}$ & है & $\stackrel{i \pi}{2}$ & $\frac{208}{2}$ \\
\hline $\begin{array}{l}\bar{\Xi} \\
\text { ( }\end{array}$ & 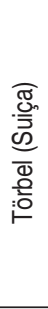 & 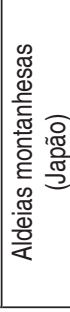 & 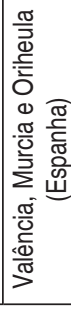 & 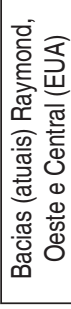 & 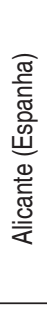 & 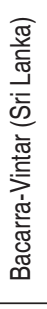 & 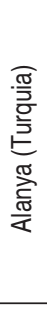 & 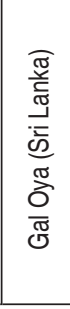 & 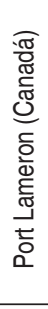 & 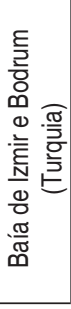 & 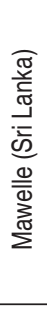 & 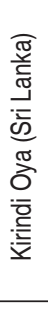 & 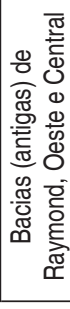 & 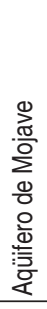 \\
\hline
\end{tabular}


Os "designs principles" estabelecem o fio condutor para a constituição da "situação" na qual os agentes atuam e interagem e, além disso, eles se prestariam tranquilamente ao falseasionismo de Popper, pois, com já se afirmou, bastaria encontrar um caso de arranjo institucional exitoso onde a maioria dos oito princípios não estivesse presente para colocar em xeque a teoria/hipótese. Araral (2013) fez um balanço nesse sentido e observou que os design principles são uma abordagem adequada para problemas de sustentabilidade de recursos em nível microeconômico, mesmo assim sujeito a ressalvas. Eles, no entanto, não são adequados para bens comuns com níveis mais agregados de complexidade (Araral, 2013:15).

Em obras posteriores, o projeto metodológico de Ostrom sofistica-se (em termos conceituais), amplia-se (em termos de incorporar contribuições epistemológicas adicionais) e torna-se mais ambicioso (uma metodologia unificada) sem abandonar, segundo nossa opinião, o compromisso básico com a abordagem popperiana. Como já foi observado, a teoria de Ostrom caminha sobre o trinômio indivíduo, situação e compreensão(previsão), que são articulados de maneira tal que cada peça, ao ensejar o diálogo com tradições estabelecidas nas Ciências Sociais, reforça o projeto mais recente de edificar uma teoria geral das instituições (Ostrom, 2005). Nada mais popperiano. Esse projeto, contudo, não pode ser conduzido a partir da atribuição de status de universalidade ao comportamento racional, ao contrário do que acreditava Popper. Os princípios gerais estão para lá dos indivíduos e existem nas estruturas mais profundas que constituem a situação da ação. Aqui a distinção entre modelo e estrutura, que já havia aparecido no livro de 1990, é retomada e enriquecida.

Em outras palavras, o projeto de Ostrom propõe-se a entender a permanência/mudança institucional como o produto da interação entre atores (sujeitos dotados de vários atributos) que interagem em várias situações da ação (situações específicas), conformando aquilo que ela chamou de arena da ação. Esta é o equivalente, conforme a própria Ostrom reconhece, ao conceito de lógica da situação de Popper (Ostrom, 2005:14). Assim, uma arena da ação "existe na casa, na vizinhança, nos conselhos locais, regionais, nacionais e internacionais, nas firmas e mercados, e na interação entre todas essas arenas com outras" (Ostrom, 2005:13). 
No capítulo 4 de "Understanding the institutional diversity", Ostrom propõe-se a explicar como e porque os agentes "escolhem entre ações" nos contextos das arenas da ação. A ausência de uma teoria da escolha foi, conforme se viu, uma das fragilidades identificadas por Hands (1992) na análise situacional de Popper. Ao buscar construir um elo ausente, Ostrom buscou complementar Popper? Embora não haja evidências explícitas nesse sentido, seria ingênuo ignorar que Ostrom estava familiarizada com o problema geral de como são feitas as escolhas pelos indivíduos. Ao realizar ampla revisão de trabalhos das mais variadas ciências, Ostrom organizou os problemas de escolha individual em três grandes hipóteses: 1) sobre como os indivíduos processam as informações e sobre seus modelos mentais; 2) sobre como ocorre o processo individual de avaliação das escolhas; 3) sobre o processo de seleção das escolhas.

As conclusões dela apontam para o abandono de um modelo único de explicação do comportamento humano, pois provavelmente faremos mais progressos se não tentarmos desenvolver um único modelo de comportamento humano que possa ser usado para prever o comportamento em todas as situações da ação de mercado e de não mercado. (Ostrom, 2005: 119/120).

\subsection{Uma nota sobre o individualismo metodológico de Ostrom}

A análise situacional de Popper, como se viu, adere explicitamente ao individualismo metodológico, inclusive em sua versão mais estrita, a do agente racional maximizador (Popper, 1993; Popper, 1985). Nossa análise aqui irá apresentar a perspectiva de Ostrom sobre o papel do indivíduo na análise econômica a partir de um artigo resenha escrito por ela inteiramente dedicado a isso. Nessa resenha (Ostrom, 1991) de seis livros, Ostrom encontrou a ocasião para realizar um balanço da situação da pesquisa teórico-empírica em Ciências Políticas, vendo aí, nessa área das Ciências Sociais, perspectivas promissoras para o desenvolvimento de um projeto de pesquisa baseado na escolha racional empiricamente fundamentado. Especificamente, no que diz respeito às Ciências Políticas, a resenha de Ostrom lhe deu ensejo para discutir dois aspectos de sua contribuição teórica que são recorrentes: 1) a dificuldade de construir uma base empírica para ciências como a Economia; 2) discutir a metodologia do indi- 
vidualismo metodológico a partir de uma perspectiva de interação indivíduo-regra. Neste aspecto, uma primeira abordagem exigiu o diálogo com autores tais como March e Olsen, que afirmavam que o comportamento é governado por regras. Sendo assim, nesta perspectiva os indivíduos justificam as escolhas utilizando o cálculo meiosfins, ao invés de conduzir uma análise prévia meios-fins para escolher uma ação. (Ostrom, 1991:239).

A reação crítica de Ostrom a este ponto de vista se estrutura como se segue. O comportamento com regras baseia-se em ações permitidas e proibidas. Estas não são passíveis de escolhas (a não ser nos casos de violação das regras), de maneira que os indivíduos que obedecem às regras se comportam conforme as regras permitidas. No entanto, as escolhas feitas no interior das regras permitidas não podem se basear em regras institucionais, ou seja, as escolhas no interior de alternativas permitidas pelas regras do jogo devem ser entendidas diferentemente da determinação do que é ou não é permitido. (Ostrom, 1991:239). Essa percepção lhe permitiu um compromisso curioso: o de aderir ao individualismo metodológico, sem desconsiderar a complexidade da tomada de decisões envolvidas em situações particulares. Esse aliás foi o tema da maior parte do seu trabalho metodológico. Para ela (Ostrom, 1991:240) Desse modo, reconhecer a importância de regras e normas sociais não é incompativel com uma interpretação da escolha racional da ação individual no interior dos constrangimentos de um conjunto ordenado de relacionamentos.

Adesão ao individualismo metodológico, e não necessariamente ao individualismo da escolha racional. Este padecia de sérias limitações, tais como o da indeterminação (ausência de um único equilíbrio) e de inadequação (ausência de conteúdo empírico para previsões). Tais limitações eram agravadas quando:

1. Analistas tentam eliminar a incerteza de ambientes inerentemente incertos;

2. Analistas reestruturam seu ponto de vista de uma situação para incluir a dimensão que conduz a respostas determinadas e ignora outras que geram a indeterminação (ausência de um equilíbrio único);

3. Analistas tentam avaliar a melhor ação em cada situação ao invés de procurar mais regras gerais que cubram muitos casos similares. 
Essa qualificação do seu individualismo metodológico é distinta da versão mais ortodoxa de Popper, mas apenas em grau, ou melhor, contexto. Ela permanece por exemplo no livro Understanding institutional diversity, de 2005, no qual a qualificação ganha mais precisão, pois nele Ostrom afirma que a escolha da hipótese que animará o modelo teórico depende da resposta a três questões vinculadas à situação: 1) a situação gera informação substantiva sobre a própria estrutura da situação?; 2) Os indivíduos entram voluntariamente na situação para competir por resultados objetivos valiosos?; 3) Aqueles que se engajam nesse tipo de situação colocam o valor principal em obter resultados objetivos imediatos da situação?

Para ela (Ostrom, 2005: 131)

Se a resposta a essas três questões conduz o analista a concluir que a situação é uma de competição aberta focada principalmente em objetivos de lucro/vantagens, então usar as hipóteses de um egoísta racional para animar o modelo é a melhor estratégia. Quando todos esses fatores estão presentes, o teórico fará previsões sobre o comportamento e o resultado que serão apoiados pelos dados empíricos. De outro lado, se a situação é um dilema social ao invés de um processo competitivo aberto, eu sustento que o analista para animar uma análise inicial assuma que participantes mantenham múltiplas orientações valorativas e utilize estratégias que vão daquelas utilizadas pelos egoístas racionais àquelas utilizadas por atores que valorizam em alto grau a confiança, a reciprocidade e a equidade.

Uma polêmica recente envolvendo Boetteke; Coyne (2005) e McGinnis ( 2005) permite discutir não apenas o individualismo de Ostrom, mas também identificar a tradição teórica na qual a contribuição dela se insere. O artigo de Boetteke; Coyne (2005) afirma, em síntese, que a reflexão científica de Ostrom continua e aprofunda o legado teórico deixado pela escola austríaca. Em outras palavras, segundo aqueles autores, ela reintroduziu na agenda da economia, com uma contribuição forte, a questão da unificação metodológica das ciências sociais, devolveu a centralidade na análise econômica 
ao indivíduo e privilegiou a compreensão, e não a predição, questões defendidas na primeira metade do século XX por Mises, Knight e Hayek. Em suma, para os autores, Ostrom estaria confortavelmente instalada na tradição liberal da escola austríaca.

O texto de McGinnis (2005) é mais cauteloso e, embora reconheça o resgate daquelas questões, aponta para a especificidade do projeto de Ostrom, que, segundo ele, referindo-se ao individualismo metodológico, "Nos começamos ai, mas não é claro para mim, no momento presente, que nós ainda operamos dentro daquela tradição como é comumente compreendida (McGinnis, 2005:170).

Por sua vez, Groenewegen (2011) pretendeu situar Elinor Ostrom e o grupo que a partir do casal Ostrom veio a se chamar The Bloomington School no campo teórico metodológico do "antigo" institucionalismo de Veblen, Commons e Mitchel, uma posição diametralmente distinta da propugnada por Boetteke; Coyne. Para eles, os Ostrom e a escola de Bloomington são herdeiros da metodologia do pragmatismo da "antiga" economia institucional, formulada por Pierce e Dewey "embora as palavras às vezes sejam diferentes" (Groenewegen, 2011:33). O problema desse tipo de argumento é o de que não há, na obra de Elinor Ostrom, referência direta ao pragmatismo ou a sua estrutura conceitual, restando assim, no caso de Groenewegen, o argumento indireto, baseado em suposta semelhança conteudística de conceitos entre a antiga economia institucional e a escola de Bloomington. Parece-nos, também, insuficiente a tentativa de Groenewegen em termos de realçar uma suposta adesão de Elinor Ostrom ao pluralismo metodológico para aparentá-la ao antigo institucionalismo, até porque a discussão de que esta escola aderiu ao pluralismo não é consenso.

Ora, conforme se buscou mostrar neste artigo, as concessões feitas por Ostrom em relação às hipóteses sobre o comportamento humano e sua ênfase na descrição e análise mais profunda da "situação" são principalmente, embora possa embutir alguma reivindicação de pluralismo, uma tentativa de aprofundar o projeto metodológico colocado por Popper para as Ciências Sociais. 


\section{Conclusões}

O artigo procurou caracterizar aspectos da proposta metodológica de Ostrom que convergem com aquela sugerida por Popper quando, principalmente em seus trabalhos tardios, discutiu o status científico das Ciências Sociais, em especial de disciplinas como a Economia. A contribuição de Popper nesse aspecto encontrou no formalismo lógico do princípio da racionalidade seu ancoradouro, e embora a dimensão "vazia" de conteúdo empírico desse princípio fosse uma fragilidade percebida por seus críticos, ele permaneceu uma referência importante para a discussão metodológica em Economia, principalmente por aqueles simpáticos à ortodoxia e às implicações em termos de liberdade individual que ela carregava.

Conforme o texto procurou argumentar, os conceitos de lógica da situação e o princípio da racionalidade de Popper exerceram forte influência sobre a metodologia de Ostrom. De alguma maneira, aquele conceito encontrou equivalente no de "arena da ação" dessa autora, e o princípio da racionalidade, despido, é claro, de qualquer ranço maximizador, permanece como base da sua teoria da agência. Em outras palavras, com a contribuição de Ostrom, a "situação" popperiana ganhou amplitude, uma estrutura conceitual articulada e amplo conteúdo empírico. Por sua vez, o "princípio da racionalidade" popperiano perdeu com a contribuição de Ostrom sua dimensão reducionista, uma vez que as hipóteses sobre o comportamento humano iam além da maximização ou da racionalidade perfeita, abrindo-se, sem tropeçar no psicologismo, para um leque variado de possibilidades comportamentais.

De um ponto de vista mais geral, Popper está presente no compromisso da autora de "abraçar a complexidade e o contexto, ou simplesmente a realidade" (Frischmann, 2013), o que exigiu dela ampliar o conteúdo empírico da análise econômica, buscando articular dedução e indução, como foi uma das tarefas empreendidas também por Popper. Desse modo, pode-se afirmar que Popper está presente na metodologia de Ostrom nas seguintes dimensões: 1) na busca de um termo de compromisso entre dedução e indução que, apesar de reconhecer a proeminência da primeira, atribuiu um papel vital ao empirismo; 2) na adesão ao individualismo metodológico em Economia, mas acrescido, no caso de Ostrom de conteúdos de complexidade, uma vez que as estruturas têm papel crucial ao con- 
dicionar comportamentos (e não determiná-los) e ao influenciar os resultados de determinado problema. Ademais, Ostrom recusava o reducionismo expresso nos modelos teóricos que se sustentavam exclusivamente em hipóteses de um indivíduo racional/maximizante; 3) no apreço, e no caso de Ostrom, numa busca viva em termos de agenda de pesquisa, pelos mecanismos de autorregulação ou autogoverno, bastante próximos àqueles de toda tradição liberal em economia (da qual, aliás, Popper era grande admirador e defensor).

Embora Popper tenha sido uma referência inspiradora para Ostrom, principalmente nos seus primeiros trabalhos, a metodologia dessa autora abriu-se a novas influencias e foi, na medida do avanço do tempo, refinando-se, ao mesmo tempo em que ampliava suas ambições. No entanto, permaneceu forte a influência popperiana, o que nos possibilita afirmar, contra análises recentes, que o programa de pesquisa científico no qual se moveu a reflexão de Ostrom permaneceu aquele da economia liberal ortodoxa, suavizado pela agenda da Nova Economia Institucional(NEI).

\section{Referências}

ARARAL, EDUARDO - Ostrom, Hardin and the commons: a critical appreciation and a revisionist view. Environmental science and policy, vol.36, pp. 11-23, 2014

BISH, R.L - Vincent Ostrom's contributions to political economy. Publius, vol.44, n.2, pp.227-248.

BOETTEKE, P.J; COYNE, C.J - Methodological individualism, spontaneous order and the research program of the Workshop in Political Theory and Policy Analysis. Journal of Economic behavior and organization, v. 57, pp. 145-158, 2005.

FRISCHMAN, BRETT. M - Two enduring lessons from Elinor Ostrom. Journal of institutional economics, v.9, n.4.pp.387-406, 2013.

FERNANDEZ, BRENA. P.M. Popper e a Economia: existe um método próprio para as ciências da sociedade? In: Oliveira, P.E (Org) - Ensaios sobre o pensamento de Popper. Curitiba:Círculo de estudos bandeirantes/PUC. 2012.pp.231-251.

GANEM, ANGELA - Karl Popper versus Theodor Adorno: lições de um confronto histórico. Revista de Economia Política, vol32, n.1, PP.87-108, 2012.

GROENEWEGEN, JOHN - The Bloomington school and American institucionalism. The good society, v.20, n.1, pp.15-36, 2011.

HANDS, WADE - Falsification, situational analysis and scientific research programs: the popperian tradition in Economics methodology. IN: De Marchi, N (Org) Post-popperian methodology of economics: recovering practice. Boston/Dordrecht/London: Kluwer Academic Publishers, 1992, pp. 19-54. 
McGINNIS, M.D - Beyond individualism and spontaneity: comments on Peter Boettke and Cristopher Coyne - Journal of Economic Behavior and Organization, vol.57, pp.167-172, 2005.

OAKLEY, ALLEN - Economics and the origin of Popper'situational analysis. History of Economics Review, n.30, pp.25-40, 1990.

OSTROM, E - Understanding institutional diversity. Princeton University Press: New Jersey, 2005.

OSTROM, E -How types of goods and property rights jointly affect collective action. Journal of Theoretical Politics, vo15, n.3, pp-239-270, 2003.

OSTROM, E - Rational choice theory and institutional analysis: toward complementarity. American Political Science Review, v.85,n.1, pp- 237-243, March 1991.

OSTROM, E - Governing the commons. Cambridge University Press: New York, 1990.

OSTROM, E - An agenda for the study of institutions. Public Choice, v.48, pp 3-25, 1986.

OSTROM, E - Beyond markets and states: polycentric governance of complex economics systems. American Economic Review, v. 100, n.3, pp.1-33, 2010.

OSTROM, E; COLE, D - The variety of property systems and rights in natural resources. IN: OSTROM, E; COLE, D (ORG)- Property in land and other resources. Lincoln institute of land policy: Massachusetts, 2012.

POPPER, K - A miséria do historicismo. São Paulo: editor Cultrix, 1993, 125p.

POPPER, K - The rationality principle. In: David Miller (Ed) Popper Selections, N.J: Princeton University Press, 1985, p 357-65.

POPPER, K - Conjecturas e refutações. In: Conjecturas e refutações. Brasília: Editora da UNB, 1980 (1963). p.63-88.

POPPER, K - A lógica da investigação científica. In: Os Pensadores. São Paulo:editora abril, 1975, PP.261-415.

SCHMID, M - The idea of rationality and its relationship to social science: comments on Popper's philosophy of the Social Sciences. Inquiry, 31, pp 451-469, 1988.

ZYLICZ, Thomaz - What economists are to learn from the economic crisis? Studia Ekonomiczne (Economic Studies), vol LXII, n.3, pp. 157- 162, 2009. 